\title{
Planning of People Management System in One of the Telecommunication Companies in Indonesia using the System Usability Scale Method
}

\author{
Muhammad Irvan Sutroyudo, Emil Robert Kaburuan
}

\begin{abstract}
At this time the application for mobile applications on an industrial scale and companies are still considered very lacking for it's application, it is because the industry that is currently running is still likely to use a desktop. Which with the mobile application opportunity and understanding of technology from everyone in the company, business process automation can be done more efficiently through mobile applications. Planning of this people management system aims to resolve the problem experienced by one of the telecommunications companies in Indonesia, which at present employees find it very difficult to make requests for overtime, leave and claims, because the current system is still in desktop or manual form filling which still depends on the office network environment. Therefore, a mobile application-based People Management System (PMS) will be made in which the process will run in real time and can be done anywhere. For the initial stages of development planning Mobile applications for People Management System (PMS) will greatly help the company problems mentioned earlier. By using Heuristic Task Analysis (HTA) as a method for reviewing the effectiveness of work and activities that are not properly carried out, so it can be obtained desirable productivity (Stanton, 2006)., and the System Usability Scale (SUS) method for interface testing which is carried out directly by end users (Martoyo \&amp; Falahah,2015). Based on the provisions of the System Usability Scale score, the assessment results of 10 respondents for the People management system application of 79.0 where the score is the Acceptability Ranges in the Acceptable category and are in grade B. From these results it is felt that there is still need for further development because current planning is for the initial planning phase, there needs to be further development to improve the performance of the company and comfort for employees.
\end{abstract}

Keywords: People Management System, Heuristic Task Analisis, System Usability Scale, HTA, SUS.

\section{INTRODUCTION}

This time the application for mobile applications on an industrial scale and companies is still considered very lacking for its application, which with the opportunity and understanding of technology from everyone in the company,

Revised Manuscript Received on December 30, 2019.

* Correspondence Author

Muhammad Irvan Sutroyudo, Information Systems Management Department, BINUS Graduate Program - Master of Information System Managements, Bina Nusantara University, Jakarta, Indonesia 11480. Email:. Email: muhammad.sutroyudo@binus.ac.id

Emil R. Kaburuan*, Information Systems Management Department, BINUS Graduate Program - Master of Information System Managements, Bina Nusantara University, Jakarta, Indonesia 11480. Email: emil.kaburuan@binus.edu

(c) The Authors. Published by Blue Eyes Intelligence Engineering and Sciences Publication (BEIESP). This is an open access article under the CC BY-NC-ND license (http://creativecommons.org/licenses/by-nc-nd/4.0/) business process automation can be done through mobile applications. Of course, the application in an application must be limited by the scope of its users because of this to ensure the security of an access to the system. Rectification in the final paper but after the final submission to the journal, rectification is not possible. Lack of neat visitor data that is still very manual cause the company is difficult to identify how many visitors enter the company environment, as well as long queues resulting in long waiting times to be served by the front office. Currently employees find it very difficult to make requests for submission of overtime, leave and claims, because the system is currently still in the form of desktop or manual form filling which still depends on the office network environment. Filing absences such as sick leave etc. sometimes goes through a very long manual approval process, and it is not uncommon to report late to the company and this will cause misunderstandings between the company and employees, and feel it is still less efficient.Based on the background of the problem, this research will create a People Management System (PMS) in which the Hierarchical Task Analysis (HTA) method is used to explore and define the tasks that must be done and needed in designing a user experience[1].and using methods system usability scale (SUS) for interface testing conducted directly by the user end user [2].The aim of this research is to produce a User Experience model using the Hierarchical Task Analysis (HTA) method that suits the needs and characteristics of the user and can be a guide or foundation in designing the User Interface that can represent the characteristics of employees and companies and determine the level of usability of the User model. Experience that has been created using the Heuristic Evaluation method, so as to ensure that the model that has been made is in accordance with the needs and characteristics of users.

\section{LITERATURE REVIEW}

\section{A. User Experience}

User Experience is something dynamic, depending on the context and subjective, which comes from a variety of potential benefits (experience) of users who come from a product [3]. By using the User Experience at the interface and mechanical design stage of an application, designers can more effectively set goals that will produce an experience. 
This is because the design has limited control to only the design part, while to measure the effectiveness of an interface design there needs to be experience from the user used [4].

\section{B. Hierarchical Task Analysis (HTA)}

Hierarchical Task Analysis is a flexible tool that can be adapted to various situations and needs. Data can come from a number of different sources, analysis can proceed to a more detailed level, and there is no rigid recipe (grip) on how the results can be used. HTA can still be done in a number of different ways that might involve greater or lesser attention [5]. HTA is a method based on the concept of performance and how to regulate work principles [6].

\section{System Usability Scale (SUS)}

To do interface testing, there are various methods, one of which is the System Usability Scale (SUS). The Usability Scale (SUS) system is part of the Usability objective where the test focuses on the interaction between software interfaces. system usability scale (SUS) is an interface test conducted directly by end users [7].

SUS testing has 10 statements as a testing tool, SUS also does not require a large number of samples so as to minimize testing costs [8]. Testing the interface with the SUS instrument has been carried out in a structured and accurately measured manner using 10 statements as benchmarks for assessment. The following is a table of 10 questions for SUS.

Table- I: SUS Testing Instrument

\begin{tabular}{|c|c|c|}
\hline No & Question & Scale \\
\hline 1 & I think that I would like to use this & $1 \mathrm{~s} / \mathrm{d}$ \\
& system frequently & 5 \\
\hline 2 & I found the system unnecessarily & $1 \mathrm{~s} / \mathrm{d}$ \\
& complex. & 5 \\
\hline 3 & I thought the system was easy to use & $1 \mathrm{~s} / \mathrm{d}$ \\
& system. & 5 \\
\hline 4 & I think that I would need the support of & $1 \mathrm{~s} / \mathrm{d}$ \\
& a technical person to be able to use this & 5 \\
\hline 5 & I found the various functions in this & $1 \mathrm{~s} / \mathrm{d}$ \\
& system were well integrated & 5 \\
\hline 6 & I thought there was too much & $1 \mathrm{~s} / \mathrm{d}$ \\
& inconsistency in this system & 5 \\
\hline 7 & I would imagine that most people & $1 \mathrm{~s} / \mathrm{d}$ \\
& would learn to use this system very & 5 \\
\hline 8 & quickly & \\
\hline 9 & I found the system very cumbersome & $1 \mathrm{~s} / \mathrm{d}$ \\
& to use & 5 \\
\hline 10 & I needed to learn a lot of things before & $1 \mathrm{~s} / \mathrm{d}$ \\
& I could get going with this system & 5 \\
\hline
\end{tabular}

\section{SUS Score Calculation Method}

The calculation of the results of software testing with the SUS instrument is carried out by following the following rules: Each statement with an odd number then the respondent's answer scale is reduced 1. Each statement with an even number is 5 minus the answer scale of the respondent. The results of a scale value of 0 to 4 (four being the most positive response). Summing the respondent's answer scale and multiplied by 2.5. Determine the average answers of all respondents [8].

\section{RESEARCH METHOD}

In this stage, will discuss how to conduct research, where there are some details that performed in this study can be seen in Figure 1. Research Stages.

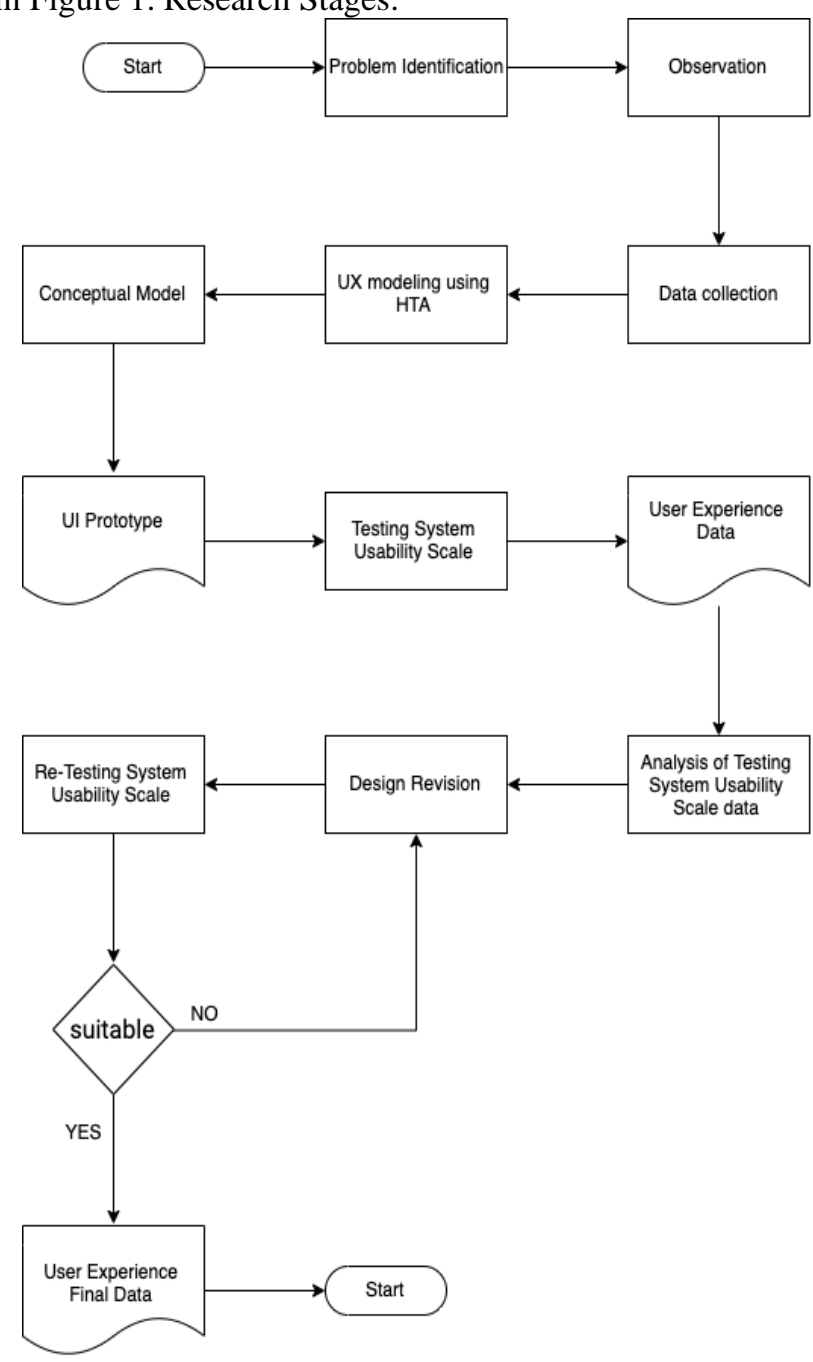

Fig. 1. Research Stages

\section{A. Interviews and Questionnaires (User persona)}

The interviews were conducted by direct observation and gave several questionnaire questions. From the results of interviews, 10 people with different user personas can be obtained, user personas are divided based on the level of ability and understanding in using the application. Then the following are the types or points of questions created based on the User Persona criteria which consist of:

- Profile

- Personality

- Technology Expertise \& User Knowledge

- References \& Influences

- Must Do / Never

- Tasks

- Additional (user likes) 


\section{B. HTA Scenario Diagram}

Following is the application scenario that has been created, the Hierarchical Task Analysis diagram is formed, which is described in figure 2 below, which will be used as a pattern or foundation in designing a conceptual model and prototype user interface or prototype of the People Management System application.

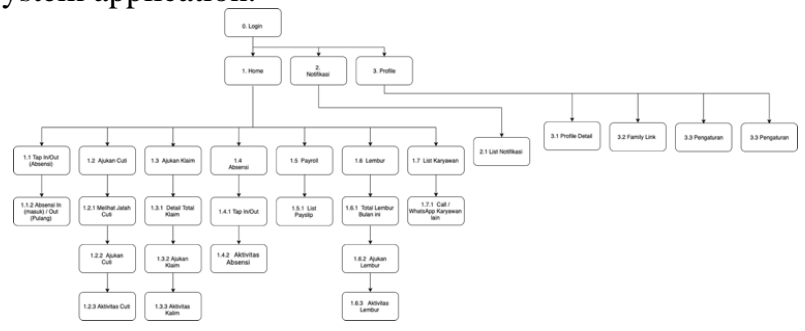

Fig. 2. Diagram of HTA People Management System

\section{Prototype}

The following is a general design in the form of topology needed in designing the People management system. Design refers to Fig. 2. Diagram of HTA People Management System that has been made. Here are some screens from the People Management System application.

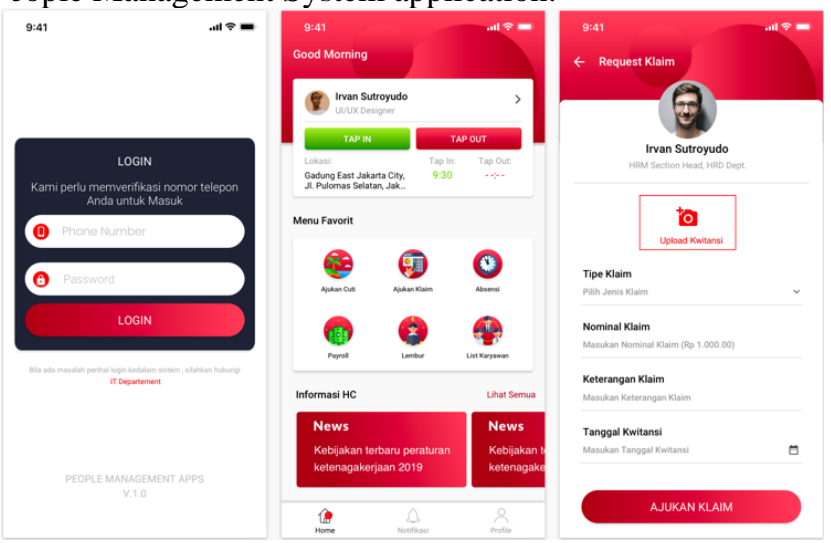

Fig. 2. User Interface People Management System

\section{Testing Method}

In testing the interface of the People Management System Application, the method used is the system usability scale (SUS). SUS can be used in conducting independent technology testing both on hardware, software, websites and even mobile devices [9]. In conducting the SUS test, it has 10 (ten) instruments as shown in Table- I: SUS Testing Instrument.

\section{RESULT}

\section{A. SUS Test Result}

The System Usability Scale (SUS) test consists of 10 respondents whom we have previously interviewed about the need for PMS applications. Characteristics of respondents consisted of different sexes, different levels of education and management levels from each division, experience of using smartphones and different ages. The results of the respondents' assessment can be seen in the table below. Where the final scale value is obtained based on the rules of the SUS Score Calculation method. The results of the respondents' assessment of the PMS Application can be seen in Table II of the System Usability Scale Test Results below:

Table- II: System Usability Scale Test Results

\begin{tabular}{|c|c|c|}
\hline Participant & Rating result & Score \\
\hline p1 & $30 * 2,5$ & 75 \\
\hline p2 & $35 * 2,5$ & 87,5 \\
\hline p3 & $29 * 2,5$ & 72,5 \\
\hline p4 & $30 * 2,5$ & 75 \\
\hline p5 & $32 * 2,5$ & 80 \\
\hline p6 & $34 * 2,5$ & 85 \\
\hline p8 & $32 * 2,5$ & 80 \\
\hline p9 & $30 * 2,5$ & 75 \\
\hline p10 & $32 * 2,5$ & 80 \\
\hline \multicolumn{2}{|c|}{ Average } & 80 \\
\hline
\end{tabular}

Based on the results of the System Usability Scale Test Results by Participants where out of 10 respondents an average score of 79.0 was obtained. After getting the final results of the respondent's assessment then the next step is to determine the grade of the assessment results. To determine the grade of assessment results there are (two) ways that can be used [10].

The first determination is seen from the side of the level of user acceptance, grade scale and rating rating which consists of the level of user acceptance, there are three categories: not acceptable, marginal and acceptable. While from the grade level scale there are six scales namely A, B, C, D, E and F. And from the rating rating consist of the worst imaginable, poor, ok, good, excellent and best imaginable as shown in Figure 3 Determination of Assessment Results [11] follows:

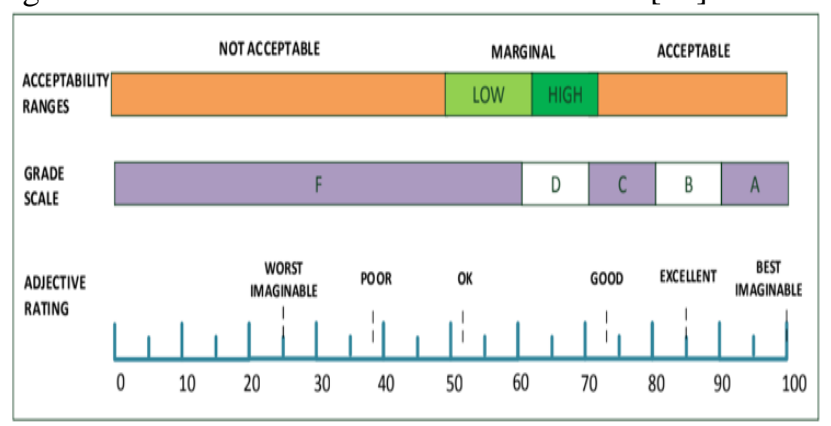

Fig. 3. Determination of Assessment Results [11]

The second determination is seen from the percentile range (SUS score) which has an assessment grade consisting of A, $\mathrm{B}, \mathrm{C}, \mathrm{D}$ and $\mathrm{F}$. From the two ways of determining the assessment results, the assessment results can be seen as follows:

- Determination of Acceptability, grade scale, adjective rating is used to see the extent of user perspective on the PMS Application. To determine the Acceptability, grade scale, and adjective rating, a comparison of the results of the average assessment of respondents was made 79.0 in Figure 3 Determination of Assessment Results the results of the assessment of respondents on the PMS application. The level of user acceptance is in the Acceptable category, the Grade Scale level is in Category C and the Adjective Rating is in the Good to Excellent category.

Published By:

Blue Eyes Intelligence Engineering \& Sciences Publication 
- For that reason in determining the SUS percentile rank score as follows: Grade A: with a score greater than or equal to 80.3; Grade B: with a greater score equal to 74 and smaller 80.3; Grade C: with a greater score of 68 and smaller 74; Grade D: with a greater score equal to 51 and smaller 68; Grade F: with a score less than 51. Based on the provisions of the determination of the SUS score, the results of the respondents' assessment of the PMS application of 79.0 are in grade $B$. So that the PMS application can be used as a supporting tool in one of the largest telecommunications companies in Indonesia.

\section{CONCLUSION}

With the Hierarchical Task Analysis method task requirements can be modeled so as to produce a User Experience model that can be a guide or foundation in designing a User Interface that can represent the characteristics of a People Management System application.

The System Usability Scale (SUS) can be used as an evaluation tool for evaluating an accurately measured and structured software interface. Based on the results of the System Usability Scale Test Results by Participants where out of 10 respondents an average score of 79.0, the level of user acceptance is in the Acceptable category. Has a variety of ways in determining the results of the evaluation as shown when evaluating the evaluation of People Management system applications.

From these results it is felt that there is still need for further development because current planning is for the initial planning phase, there needs to be further development to improve the performance of the company and comfort for employees.

\section{REFERENCES}

1. Stanton, N. (2006). Hierarchical task analysis: Developments, applications, and extensions. Applied Ergonomics, 37, 55-79. https://doi.org/10.1016/j.apergo.2005.06.003

2. Martoyo, W. U., \& Falahah. (2015). Kajian Evaluasi Usability dan Utility pada Situs Web. Seminar Nasional Sistem Informasi Indonesia (pp. 537-543). Surabaya: Institut Teknologi Sepuluh November.

3. Effie L-C. Law , Virpi Roto, Marc Hassenzahl, Arnold P.O.S. Vermeeren, Joke Kort, Understanding, Scoping and ining User eXperience: A Survey Approach. Europe: ACM, 2009.

4. Winn, M. a., The Design, Play, And Experience Framework. Michigan, Michigan, USA: Michigan State University, 2006.

5. Lawrence.Erlbaum.Assoc, The Handbook of Task Analysis for Human Computer Interaction, Neville Stanton Danper, Ed. Mahwah, New Jersey, USA: LAWRENCE ERLBAUM ASSOCIATES, PUBLISHERS, 2004.

6. Stanton, N. (2006). Hierarchical task analysis: Developments, applications, and extensions. Applied Ergonomics, 37, 55-79. https://doi.org/10.1016/j.apergo.2005.06.003

7. Martoyo, W. U., \& Falahah. (2015). Kajian Evaluasi Usability dan Utility pada Situs Web. Seminar Nasional Sistem Informasi Indonesia (pp. 537-543). Surabaya: Institut Teknologi Sepuluh November.

8. Brooke, J. (1996). SUS - A quick and dirty usability scale. United Kingdom: Redhatch Consulting Ltd.

9. Sauro, J. (2011). A Practical Guide to the System Usability Scale: Background, Benchmarks \& Best Practices. North Charleston SC: Create Space Independent Publishing Platform.

10. Brooke, J. (2013). SUS: A Retrospective. Journal of Usability Studies, $29-40$

11. Bangor, A., Kortum, P. T., \& Miller, J. (2009).Determining what individual SUS scores mean: Adding an adjective rating scale. Journal of usability studies , 114-123.

\section{AUTHORS PROFILE}

Muhammad Irvan Sutroyudo, is a graduated master's degree in Binus Univeristy. He has interests in human interaction and technology. He has been working at Telecommunication industry in Indonesia as a UI/UX Designer. Jakarta, Indonesia Irvan.sutroyudo@gmail.com

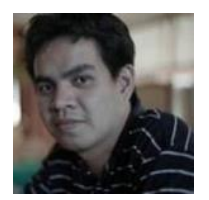

Emil R. Kaburuan, is a full-time faculty at Binus Graduate school. He has interests in human and technology. He has been working in several countries including Post-doctoral at Swedish institute of Computer Science (SICS) with the funding from the European Research Consortium for Informatics and. Mathematics (ERCIM) Fellowship. He has been invited to share his researches and involved in several international collaboration projects. Jakarta, Indonesia. emil.kaburuan@binus.edu 